\title{
Estradiol meets Notch signaling in developing neurons
}

\section{María Angeles Arevalo ${ }^{1}$, Isabel Ruiz-Palmero ${ }^{1}$, Julia Simon-Areces ${ }^{1}$, Estefanía Acaz-Fonseca ${ }^{1}$, Iñigo Azcoitia ${ }^{2}$ and Luis Miguel Garcia-Segura ${ }^{1}$ *}

1 Instituto Cajal, Consejo Superior de Investigaciones Científicas, Madrid, Spain

${ }^{2}$ Facultad de Biología, Biología Celular, Universidad Complutense de Madrid, Madrid, Spain

\section{Edited by:}

Hubert Vaudry, University of Rouen,

France

Reviewed by:

Gabriele M. Rune,

Universitätsklinikum

Hamburg-Eppendorf, Germany

EiTerasawa, University of Wisconsin-

Madison, USA

\section{*Correspondence:}

Luis Miguel Garcia-Segura, Instituto

Cajal, Consejo Superior de

Investigaciones Científicas, Avenida

Doctor Arce 37, E-28002 Madrid,

Spain.

e-mail:Imgs@cajal.csic.es
The transmembrane receptor Notch, a master developmental regulator, controls gliogenesis, neurogenesis, and neurite development in the nervous system. Estradiol, acting as a hormonal signal or as a neurosteroid, also regulates these developmental processes. Here we review recent evidence indicating that estradiol and Notch signaling interact in developing hippocampal neurons by a mechanism involving the putative membrane receptor $\mathrm{G}$ protein-coupled receptor 30 . This interaction is relevant for the control of neuronal differentiation, since the downregulation of Notch signaling by estradiol results in the upregulation of neurogenin 3, which in turn promotes dendritogenesis.

Keywords: dendritogenesis, estrogen receptors, G protein-coupled estrogen receptor, G protein-coupled receptor 30 , hairy and enhancer of split, neurogenin 3
INTRODUCTION: DEVELOPMENTAL ACTIONS OF ESTRADIOL

Estradiol is a neuroactive steroid that exerts hormonal as well as local paracrine or autocrine actions in the central nervous system, during development and in adulthood. Estradiol is produced in the ovary and in other tissues by the enzyme aromatase, which, in the brain, is expressed by specific neuronal populations (Roselli et al., 2009; Azcoitia et al., 2011). Brain aromatase and local estradiol synthesis participate in the regulation of brain development. For instance, aromatase is expressed by neural progenitor cells in vertebrates (Mouriec et al., 2008) and it is involved in the regulation of neural progenitor cell proliferation in the embryonic cerebral cortex of mice (Martinez-Cerdeno et al., 2006). In addition, many of the developmental effects of hormonal testosterone on male brain sexual differentiation are mediated by its local conversion to estradiol by neurons expressing the enzyme aromatase (MacLusky and Naftolin, 1981; Roselli et al., 2009). Furthermore, recent evidence indicate that estradiol also participates in the regulation of brain sexual differentiation in females (Bakker and Brock, 2010; Brock et al., 2011).

In addition to regulate the proliferation of neural progenitor cells (Martinez-Cerdeno et al., 2006), estradiol modulates the development of postmitotic neurons, affecting the growth of axons, dendrites and dendritic spines, and the formation of synapses (Ferreira and Caceres, 1991; Díaz et al., 1992; Duenas et al., 1996; Beyer and Karolczak, 2000; Woolley, 2000; Blacklock et al., 2005; Tsutsui, 2006; Miñano et al., 2008; Bender et al., 2010). These developmental actions depend in many cases of local estradiol synthesis (Kretz et al., 2004; Tsutsui, 2006; von Schassen et al., 2006; Hu et al., 2007; Sasahara et al., 2007).

\section{NOTCH SIGNALING IN NEURAL DEVELOPMENT}

Notch is a transmembrane receptor involved in cell to cell communication. The activation of Notch by transmembrane ligands,
Delta-like, and Jagged, results in the cleavage of the molecule and the release of a Notch intracellular domain that is translocated to the cell nucleus and regulates transcriptional activity (Lai, 2004). Notch signaling controls cell-fate specification, differentiation, proliferation, and apoptosis in developing tissues (ArtavanisTsakonas et al., 1999). In the nervous system, Notch signaling regulates neurogenesis and gliogenesis, not only during development but also in the adult brain (Louvi and Artavanis-Tsakonas, 2006; Ables et al., 2011; Pierfelice et al., 2011). In developing neurons, Notch signaling inhibits neurite outgrowth. In contrast, the inhibition of Notch signaling promotes neurite extension (Berezovska et al., 1999; Sestan et al., 1999; Salama-Cohen et al., 2005).

The activation of Notch signaling in developing hippocampal neurons in vitro (Figure 1) is associated with an increase in the expression of the transcription factors hairy and enhancer of split (Hes) 1 and 5 (Salama-Cohen et al., 2005). Hes transcription factors regulate the expression of several genes involved in cell differentiation. One of such genes is the basic helix-loop-helix transcription factor neurogenin 3 (Ngn3), which in developing pancreas is a proendocrine gene that causes the differentiation of the four endocrine cell lineages (Lee et al., 2001; Rukstalis and Habener, 2009) and that it is downregulated by Notch signaling via Hes1 (Lee et al., 2001). Activation of Notch signaling in neurons also induces a decrease in the expression of Ngn3 (Salama-Cohen et al., 2006). Ngn3 participates in different developmental events in the central nervous system. In the developing spinal cord, Ngn3 is expressed in glial precursor cells and it is necessary for the normal differentiation of mature oligodendrocytes and astrocytes (Lee et al., 2003). In chick embryos, Ngn3 promotes early retinal neurogenesis (Ma et al., 2009). In the hypothalamus, Ngn3 regulates the differentiation of several neuronal populations, including proopiomelanocortin (POMC) and neuropetide Y (NPY) neurons, which play a central role in energy balance and the control of food intake 


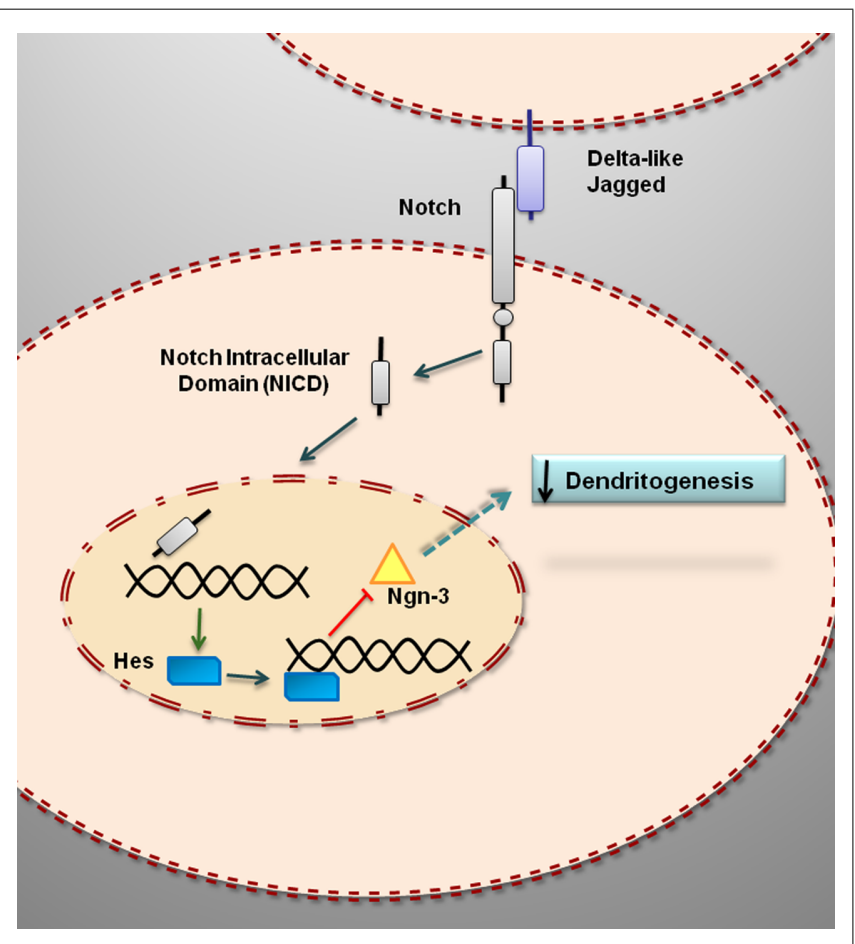

FIGURE 1 | Notch signaling represses dendritogenesis in developing hippocampal neurons by downregulating the expression of

neurogenin 3. The binding of Notch ligands (Delta-like, Jagged) results in the cleavage of Notch and the release of an active intracellular domain that is translocated to the cell nucleus where it enhances the transcription of target genes, such as Hes1, that repress the transcription of Ngn3. Ngn3 encodes for a protein, neurogenin 3 , which promotes dendritogenesis.

(Pelling et al., 2011). In hippocampal neurons, Ngn3 promotes the growth of dendrites and regulates the number of afferent GABAergic synaptic inputs (Salama-Cohen et al., 2006). Therefore, the activation of Notch in developing hippocampal neurons represses the process of dendritogenesis by the downregulation of Ngn3 (Figure 1).

\section{CROSS-TALK BETWEEN ESTRADIOL AND NOTCH SIGNALING}

Cross-talk between estradiol and Notch signaling has been detected in breast cancer cells and endothelial cells (Soares et al., 2004; Sobrino et al., 2009). Furthermore, the estrogenic compound genistein downregulates Notch-1 in prostate cancer cells (Wang et al., 2006, 2011). In breast cancer cells, estradiol decreases Notch transcriptional activity via an estrogen receptor (ER) $\alpha$-mediated inhibition of Notch cleavage by $\gamma$-secretase (Rizzo et al., 2008). In turn, Notch-1 activates ER $\alpha$-dependent transcription in these cells in the presence or absence of estradiol (Hao et al., 2010). Therefore, estradiol regulates Notch signaling and Notch signaling regulates estrogen signaling in breast cancer cells. It remains to be determined whether the cross-regulation of estrogen and Notch signaling also occurs in other cell types. Given the importance of Notch signaling for brain development, it is important to explore whether such interaction takes place in neural cells.

Recent studies have shown that estradiol reduces the levels of the intracellular transcriptionally active domain of Notch-1 in

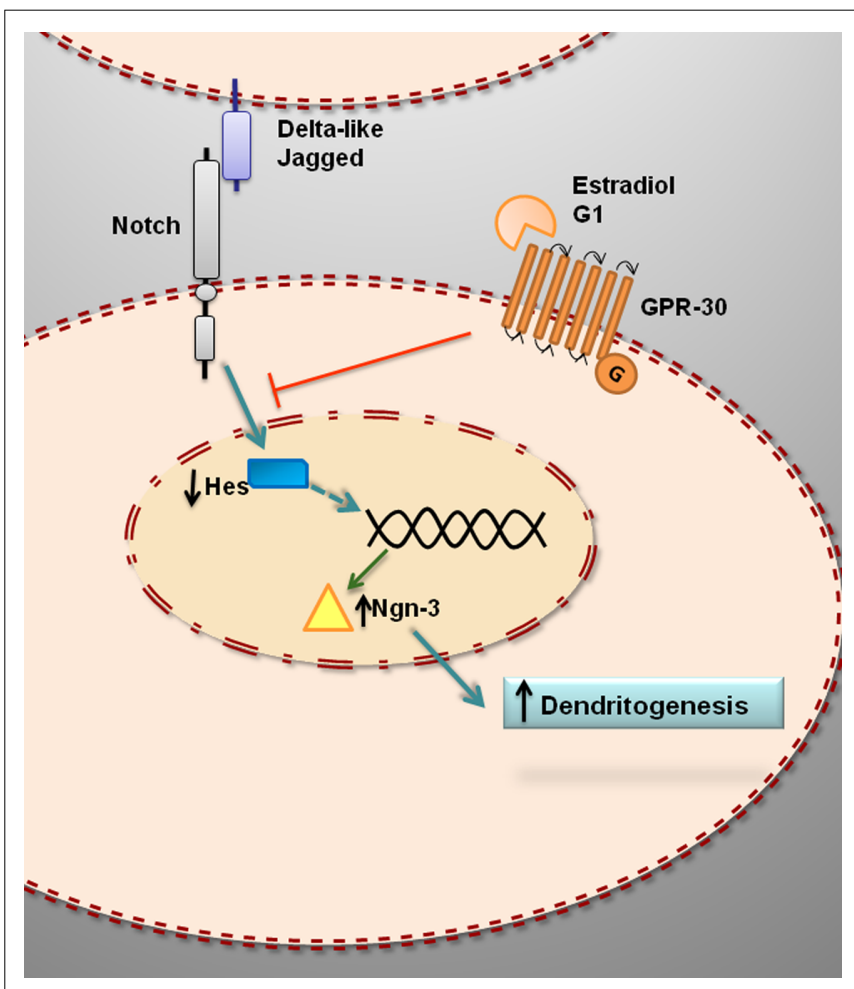

FIGURE 2 | Hypothetical model for the estrogenic regulation of $\mathrm{Ngn} 3$ and dendritogenesis in primary hippocampal neurons. Estradiol downregulates Hes genes and upregulates $\mathrm{Ngn} 3$, which in turn promotes dendritogenesis. The effect of estradiol is not imitated by ER $\alpha$ or ER $\beta$ agonists and it is not blocked by $E R \alpha$ or $E R \beta$ antagonists. In contrast, G1, agonist of the putative membrane estrogen receptor GPR30, imitate the effect of estradiol on $\mathrm{Ngn} 3$ expression and dendritogenesis, suggesting that the action of estradiol is mediated by GPR30.

hippocampal slice cultures (Bender et al., 2010). This suggests that estradiol may decrease Notch-1 mediated transcription in hippocampal cells by reducing Notch-1 cleavage (Figure 2). In primary cultures of mice hippocampal neurons, estradiol decreases the expression of Hes 1 and increases the expression of Ngn3 (Ruiz-Palmero et al., 2011). These findings further indicate that estradiol downregulates Notch signaling in hippocampal neurons (Figure 2).

G protein-coupled receptor 30 (GPR30), also known as $G$ protein-coupled estrogen receptor (GPER), is a putative membrane associated ER (Prossnitz et al., 2008; Olde and LeebLundberg, 2009; Prossnitz and Maggiolini, 2009; Langer et al., 2010). GPR30 seems to be involved in the regulation of Notch signaling in hippocampal neurons, since G1, a ligand of GPR30 that imitates the effects of estradiol in different cell types and tissues (Terasawa et al., 2009; Zhang et al., 2010) also imitates the effect of estradiol on Ngn3 expression in hippocampal neurons (Ruiz-Palmero et al., 2011). In contrast, neither the ER $\alpha$ agonist 4, $4^{\prime}, 4^{\prime \prime}$-(4-Propyl-[1H]-pyrazole-1,3,5-triyl) trisphenol (PPT) nor the ER $\beta$ agonist 2,3-bis (4-Hydroxyphenyl)propionitrile (DPN) affect the expression of Ngn3 in hippocampal neurons (Ruiz-Palmero et al., 2011). In addition, 
1,3-Bis (4-hydroxyphenyl)-4-methyl-5-[4-(2-piperidinylethoxy) phenol]-1H-pyrazole (MPP) and 4-[2-Phenyl-5,7-bis (trifluoromethyl) pyrazolo [1,5-a] pyrimidin-3-yl] phenol (PHTPP), selective antagonists of ER $\alpha$ and ER $\beta$ mediated transcription, respectively, do not antagonize the effect of estradiol on Ngn3 expression (Ruiz-Palmero et al., 2011). Furthermore, ICI 182,780 (ICI), antagonist of both ER $\alpha$ and ER $\beta$ mediated transcription and agonist of GPR30 (Thomas et al., 2005), not only does not block, but even imitates, the effect of estradiol on Ngn3 expression (Ruiz-Palmero et al., 2011). Therefore, estradiol may regulate Ngn3 levels in hippocampal neurons by a non-canonical mechanism, which probably is independent of classical nuclear ER mediated transcription.

\section{ESTRADIOL PROMOTES DENDRITOGENESIS IN HIPPOCAMPAL NEURONS BY A MECHANISM INVOLVING $\mathrm{Ngn} 3$}

The neuritogenic action of estradiol is mediated by the activation of the mitogen activated protein kinase (MAPK) cascade among other signaling mechanisms (Carrer et al., 2003, 2005; Dominguez et al., 2004; Gorosito and Cambiasso, 2008; Miñano et al., 2008). Recent studies have assessed whether Notch signaling is also involved in the neuritogenic actions of estradiol. Estradiol promotes dendritogenesis in primary hippocampal neurons

\section{REFERENCES}

Ables, J. L., Breunig, J. J., Eisch, A. J., and Rakic, P. (2011). Not(ch) just development: notch signalling in the adult brain. Nat. Rev. Neurosci. 12, 269-283.

Artavanis-Tsakonas, S., Rand, M. D., and Lake, R. (1999). Notch signaling: cell fate control and signal integration in development. Science 284, 770-776.

Azcoitia, I., Yague, J. G., and GarciaSegura, L. M. (2011). Estradiol synthesis within the human brain. $\mathrm{Neu}$ roscience 191, 139-147.

Bakker, J., and Brock, O. (2010). Early oestrogens in shaping reproductive networks: evidence for a potential organisational role of oestradiol in female brain development. J. Neuroendocrinol. 22, 728-735.

Bender, R. A., Zhou, L., Wilkars, W., Fester, L., Lanowski, J. S., Paysen, D., König, A., and Rune, G. M. (2010). Roles of $17 ß$-estradiol involve regulation of reelin expression and synaptogenesis in the dentate gyrus. Cereb. Cortex 20, 2985-2995.

Berezovska, O., McLean, P., Knowles, R., Frosh, M., Lu, F. M., Lux, S. E., and Hyman, B. T. (1999). Notch1 inhibits neurite outgrowth in postmitotic primary neurons. Neuroscience 93, 433-439.

Beyer, C., and Karolczak, M. (2000). Estrogenic stimulation of neurite growth in midbrain dopaminergic neurons depends on cAMP/protein kinase A signaling. J. Neurosci. Res. 59, 107-116.

Blacklock, A. D., Johnson, M. S., Krizsan-Agbas, D., and Smith, P. G. (2005). Estrogen increases sensory nociceptor neuritogenesis in vitro by a direct, nerve growth factorindependent mechanism. Eur. J. Neurosci. 21, 2320-2328.

Brock, O., Baum, M. J., and Bakker, J. (2011). The development of female sexual behavior requires pre5574-5578.

Carrer, H. F., Cambiasso, M. J., Brito, V., and Gorosito, S. (2003). Neurotrophic factors and estradiol interact to control axogenic growth in hypothalamic neurons. Ann. N. Y. Acad. Sci. 1007, 306-316.

Carrer, H. F., Cambiasso, M. J., and Gorosito, S. (2005). Effects of estrogen on neuronal growth and differentiation. J. Steroid Biochem. Mol. Biol. 93, 319-323.

Díaz, H., Lorenzo, A., Carrer, H. F., and Cáceres, A. (1992). Time lapse study of neurite growth in hypothalamic dissociated neurons in culture: sex differences and estrogen effects. J. Neurosci. Res. 33, 266-281.

Dominguez, R., Jalali, C., and de Lacalle, S. (2004). Morphological effects of estrogen on cholinergic neurons in vitro involves activation of extracellular signal-regulated kinases. $J$. Neurosci. 24, 982-990. pubertal estradiol. J. Neurosci. 31, in culture; this effect is imitated by G1 and it is not blocked by ICI (Ruiz-Palmero et al., 2011). Furthermore, neither G1 nor estradiol promote dendritogenesis in hippocampal neurons when Ngn3 is downregulated using Ngn3-specific siRNA oligonucleotides (Ruiz-Palmero et al., 2011). Therefore estradiol and G1 may act through common mechanisms to regulate Ngn3 expression and dendritogenesis by the inhibition of Notch signaling (Figure 2).

\section{CONCLUSION}

The studies reviewed here indicate that estradiol interacts with Notch signaling in the nervous system. Estradiol regulates dendritogenesis in developing hippocampal neurons through the modulation of Notch signaling and the upregulation of Ngn3 by a mechanism involving the putative membrane ER GPR30. Further studies are necessary to determine whether this mechanism also operates in other neuronal types. In addition, new experiments are needed to clarify the molecular mechanisms linking estrogen/GPR30 and Notch signaling in neurons.

\section{ACKNOWLEDGMENTS}

The authors acknowledge financial support from the Ministerio de Ciencia e Innovación, Spain (BFU2008-02950-C03-01/02), and from Comunidad de Madrid (CCG08-CSIC/SAL-3617).
Duenas, M., Torres-Aleman, I., Naftolin, F., and Garcia-Segura, L. M. (1996). Interaction of insulin-like growth factor-I and estradiol signaling pathways on hypothalamic neuronal differentiation. Neuroscience 74, 531-539.

Ferreira, A., and Caceres, A. (1991). Estrogen-enhanced neurite growth: evidence for a selective induction of Tau and stable microtubules. J. Neurosci. 11, 392-400.

Gorosito, S. V., and Cambiasso, M. J. (2008). Axogenic effect of estrogen in male rat hypothalamic neurons involves $\mathrm{Ca}(2+)$, protein kinase $\mathrm{C}$, and extracellular signal-regulated kinase signaling. J. Neurosci. Res. 86, 145-157.

Hao, L., Rizzo, P., Osipo, C., Pannuti, A., Wyatt, D., Cheung, L. W., Sonenshein, G., Osborne, B. A., and Miele, L. (2010). Notch-1 activates estrogen receptor-alpha-dependent transcription via IKKalpha in breast cancer cells. Oncogene 29, 201-213.

Hu, R., Cai, W. Q., Wu, X. G., and Yang, Z. (2007). Astrocyte-derived estrogen enhances synapse formation and synaptic transmission between cultured neonatal rat cortical neurons. Neuroscience 144, 1229-1240.

Kretz, O., Fester, L., Wehrenberg, U., Zhou, L., Brauckmann, S., Zhao, S., Prange-Kiel, J., Naumann, T., Jarry, H., Frotscher, M., and Rune, G. M. (2004). Hippocampal synapses depend on hippocampal estrogen synthesis. J. Neurosci. 24, 5913-5921.

Lai, E. C. (2004). Notch signaling: control of cell communication and cell fate. Development 131, 965-973.

Langer, G., Bader, B., Meoli, L., Isensee, J., Delbeck, M., Noppinger, P. R., and Otto, C. (2010). A critical review of fundamental controversies in the field of GPR30 research. Steroids 75, 603-610.

Lee, J., Wu, Y., Qi, Y., Xue, H., Liu, Y., Scheel, D., German, M., Qiu, M., Guillemot, F., Rao, M., and Gradwohl, G. (2003). Neurogenin3 participates in gliogenesis in the developing vertebrate spinal cord. Dev. Biol. 253, 84-98.

Lee, J. C., Smith, S. B., Watada, H., Lin, J., Scheel, D., Wang, J., Mirmira, R. G., and German, M. S. (2001). Regulation of the pancreatic proendocrine gene neurogenin3. Diabetes 50, 928-936.

Louvi, A., and Artavanis-Tsakonas, S. (2006). Notch signalling in vertebrate neural development. Nat. Rev. Neurosci. 7, 93-102.

Ma, W., Yan, R. T., Mao, W., and Wang, S. Z. (2009). Neurogenin 3 promotes early retinal neurogenesis. Mol. Cell. Neurosci. 40, 187-198.

MacLusky, N. J., and Naftolin, F. (1981). Sexual differentiation of the central nervous system. Science 211, 1294-1302. 
Martinez-Cerdeno, V., Noctor, S. C., and Kriegstein, A. R. (2006). Estradiol stimulates progenitor cell division in the ventricular and subventricular zones of the embryonic neocortex. Eur. J. Neurosci. 24, 3475-3488.

Miñano, A., Xifró, X., Pérez, V., Barneda-Zahonero, B., Saura, C. A., and Rodríguez-Alvarez, J. (2008). Estradiol facilitates neurite maintenance by a Src/Ras/ERK signalling pathway. Mol. Cell. Neurosci. 39, 143-151.

Mouriec, K., Pellegrini, E., Anglade, I., Menuet, A., Adrio, F., Thieulant, M. L., Pakdel, F., and Kah, O. (2008). Synthesis of estrogens in progenitor cells of adult fish brain: evolutive novelty or exaggeration of a more general mechanism implicating estrogens in neurogenesis? Brain Res. Bull. 75, 274-280.

Olde, B., and Leeb-Lundberg, L. M. (2009). GPR30/GPER1: searching for a role in estrogen physiology. Trends Endocrinol. Metab. 20, 409-416.

Pelling, M., Anthwal, N., McNay, D., Gradwohl, G., Leiter, A. B., Guillemot, F., and Ang, S. L. (2011). Differential requirements for neurogenin 3 in the development of POMC and NPY neurons in the hypothalamus. Dev. Biol. 349, 406-416.

Pierfelice, T., Alberi, L., and Gaiano, N. (2011). Notch in the vertebrate nervous system: an old dog with new tricks. Neuron 69, 840-855.

Prossnitz, E. R., and Maggiolini, M. (2009). Mechanisms of estrogen signaling and gene expression via GPR30. Mol. Cell. Endocrinol. 308, 32-38.

Prossnitz, E. R., Oprea, T. I., Sklar, L. A., and Arterburn, J. B. (2008). The ins and outs of GPR30: a transmembrane estrogen receptor. J. Steroid Biochem. Mol. Biol. 109, 350-353.

Rizzo, P., Miao, H., D’Souza, G., Osipo, C., Song, L. L., Yun, J., Zhao, H.,
Mascarenhas, J., Wyatt, D., Antico, G., Hao, L., Yao, K., Rajan, P., Hicks, C., Siziopikou, K., Selvaggi, S., Bashir, A., Bhandari, D., Marchese, A., Lendahl, U., Qin, J. Z., Tonetti, D. A., Albain, K., Nickoloff, B. J., and Miele, L. (2008). Cross-talk between notch and the estrogen receptor in breast cancer suggests novel therapeutic approaches. Cancer Res. 68, 5226-5235.

Roselli, C. E., Liu, M., and Hurn, P. D. (2009). Brain aromatization: classic roles and new perspectives. Semin. Reprod. Med. 27, 207-217.

Ruiz-Palmero, I., Simon-Areces, J., Garcia-Segura, L. M., and Arevalo, M. A. (2011). Notch/neurogenin 3 signalling is involved in the neuritogenic actions of oestradiol in developing hippocampal neurones. J. Neuroendocrinol. 23, 355-364.

Rukstalis, J. M., and Habener, J. F. (2009). Neurogenin3: a master regulator of pancreatic islet differentiation and regeneration. Islets 1, 177-184.

Salama-Cohen, P., Arevalo, M. A., Grantyn, R., and RodriguezTebar, A. (2006). Notch and NGF/p75(NTR) control dendrite morphology and the balance of excitatory/inhibitory synaptic input to hippocampal neurones through neurogenin 3. J. Neurochem. 97, 1269-1278.

Salama-Cohen, P., Arevalo, M. A., Meier, J., Grantyn, R., and RodriguezTebar, A. (2005). NGF controls dendrite development in hippocampal neurons by binding to p75(NTR) and modulating the cellular targets of notch. Mol. Biol. Cell 16, 339-347.

Sasahara, K., Shikimi, H., Haraguchi, S., Sakamoto, H., Honda, S., Harada, N., and Tsutsui, K. (2007). Mode of action and functional significance of estrogen-inducing dendritic growth, spinogenesis, and synaptogenesis in the developing Purkinje cell. J. Neurosci. 27, 7408-7417.

Sestan, N., Artavanis-Tsakonas, S., and Rakic, P. (1999). Contact-dependent inhibition of cortical neurite growth mediated by notch signaling. Science 286, 741-746.

Soares, R., Balogh, G., Guo, S., Gartner, F., Russo, J., and Schmitt, F. (2004). Evidence for the notch signaling pathway on the role of estrogen in angiogenesis. Mol. Endocrinol. 18, 2333-2343.

Sobrino, A., Mata, M., LagunaFernandez, A., Novella, S., Oviedo, P. J., García-Pérez, M. A., Tarín, J. J., Cano, A., and Hermenegildo, C. (2009). Estradiol stimulates vasodilatory and metabolic pathways in cultured human endothelial cells. PLoS ONE 4, e8242. doi: 10.1371/journal.pone.0008242

Terasawa, E., Noel, S. D., and Keen, K. L. (2009). Rapid action of oestrogen in luteinising hormone-releasing hormone neurones: the role of GPR30. J. Neuroendocrinol. 21, 316-321.

Thomas, P., Pang, Y., Filardo, E. J., and Dong, J. (2005). Identity of an estrogen membrane receptor coupled to a $\mathrm{G}$ protein in human breast cancer cells. Endocrinology 146, 624-632.

Tsutsui, K. (2006). Biosynthesis and organizing action of neurosteroids in the developing Purkinje cell. Cerebellum 5, 89-96.

von Schassen, C., Fester, L., Prange-Kiel, J., Lohse, C., Huber, C., Böttner, M., and Rune, G. M. (2006). Oestrogen synthesis in the hippocampus: role in axon outgrowth. J. Neuroendocrinol. 18, 847-856.

Wang, Z., Li, Y., Ahmad, A., Banerjee, S., Azmi, A. S., Kong, D., Wojewoda, C., Miele, L., and Sarkar, F. H. (2011). Down-regulation of Notch-1 is associated with Akt and FoxM1 in inducing cell growth inhibition and apoptosis in prostate cancer cells. J. Cell. Biochem. 112, 78-88.

Wang, Z., Zhang, Y., Banerjee, S., Li, Y., and Sarkar, F. H. (2006). Inhibition of nuclear factor kappab activity by genistein is mediated via Notch-1 signaling pathway in pancreatic cancer cells. Int. J. Cancer 118, 1930-1936.

Woolley, C. S. (2000). Effects of oestradiol on hippocampal circuitry. Novartis Found. Symp. 230, 173-180.

Zhang, B., Subramanian, S., Dziennis, S., Jia, J., Uchida, M., Akiyoshi, K., Migliati, E., Lewis, A. D., Vandenbark, A. A., Offner, H., and Hurn, P. D. (2010). Estradiol and G1 reduce infarct size and improve immunosuppression after experimental stroke. J. Immunol. 184, 4087-4094.

Conflict of Interest Statement: The authors declare that the research was conducted in the absence of any commercial or financial relationships that could be construed as a potential conflict of interest.

Received: 15 July 2011; accepted: 31 July 2011; published online: 11 August 2011.

Citation: Arevalo MA, Ruiz-Palmero I, Simon-Areces J, Acaz-Fonseca E, Azcoitia $I$ and Garcia-Segura LM (2011) Estradiol meets Notch signaling in developing neurons. Front. Endocrin. 2:21. doi: 10.3389/fendo.2011.00021

This article was submitted to Frontiers in Neuroendocrine Science, a specialty of Frontiers in Endocrinology.

Copyright (C) 2011 Arevalo, RuizPalmero, Simon-Areces, Acaz-Fonseca, Azcoitia and Garcia-Segura. This is an open-access article subject to a nonexclusive license between the authors and Frontiers Media SA, which permits use, distribution and reproduction in other forums, provided the original authors and source are credited and other Frontiers conditions are complied with. 